\title{
Geo-chemo-mechanical characterization of a polluted marine basin
}

\author{
Francesca Sollecito $^{* 1}$, Federica Cotecchia ${ }^{1}$, Matilda Mali $^{1}$, Daniela Miccoli ${ }^{1}$, Claudia Vitone $^{1}$ \\ ${ }^{1}$ Politecnico di Bari, DICATECh, 70125 Bari, Italy
}

\begin{abstract}
The work shows the first results of the characterization of the heavily polluted sediments in the Mar Piccolo basin (Taranto, south of Italy), obtained thanks to an integrated investigation method. In the field of the actions promoted by the Italian Government to select the most sustainable remediation strategies, a multidisciplinary investigation of the site has been carried out involving the reconstruction of the geological set-up of the basin, the analysis of the chemical contamination and the geo-mechanical properties of the sediments collected up to $30 \mathrm{~m}$ below the sea floor. The devices and methodologies used for the off-shore sampling, storage and transport of the sediments and for the laboratory testing were specifically designed to obtain the best possible picture of the site. The quality of the soil sampling resulted to be high enough for chemical, geochemical and geotechnical characterization and to develop integrated analyses. With this purpose, the paper discusses preliminary correlations of data, focusing on the geotechnical properties of plasticity that have been interpreted in the light of soil composition and chemical and geological facets of the sediments.
\end{abstract}

\section{Introduction}

The site under the study is the Mar Piccolo basin (literally "Little Sea"), a semi-enclosed basin having a total surface of $20.72 \mathrm{~km}^{2}$ and $13 \mathrm{~m}$ of maximum water depth. The basin is divided into the so-called First and Second Bay (Fig. 1) and is located just behind the coast of the city of Taranto (South of Italy). The town is one of the most important industrial sites in Europe, which has been declared 'at high risk of environmental crisis' and included into the list of the Sites of National Interest (SIN; [1]), to be subjected to environmental remediation. Probably, due to the inflow of fresh water by submarine springs (e.g. Galeso and Citrello in Fig.1) and tributary rivers, the peculiar morphology and the climatic conditions of the area, the Mar Piccolo represents an unusual ecosystem from the naturalistic point of view and hosts several plant and animal protected species and the most important area of mussel farming in Italy [2].

In 2016-2017 an ample investigation campaign was funded by the Special Commissioner for urgent measures of reclamation, environmental improvements and redevelopment of Taranto (CS_2017 hereafter), aimed to the multidisciplinary investigation of the sediments in the First Bay for the selection of the most suitable remediation strategies [3]. Usually, the environmental campaigns in contaminated sites tend to characterize in more detail the physical and chemical properties of the shallow layer, that is expected to be directly affected by the contamination. The CS_2017 campaign has focused on the geotechnical engineering volume of sediments (i.e. from shallow to large depths) by considering it simultaneously with the chemical composition and the geological and morphological evolution of the whole basin over time.

This inherently interdisciplinary approach addressed the selection of the most sustainable remediation scenarios because on one side allowed the identification of hot-spots along vertical profiles, on the other, supported both the identification of loading factors controlling the spatial migration of contaminants and the reliable assessment of their far-reaching combination effects. Additionally, the sampling and testing procedures have been defined in such a way to enable the data integration, respecting the strict protocols required for the chemical, geotechnical and environmental characterization and the time and cost-efficiency criteria [4].

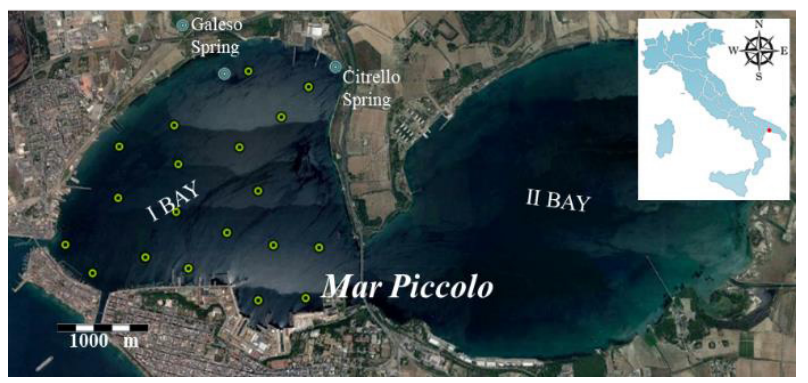

Fig. 1. Mar Piccolo basin in Taranto (Southern Italy). The green dots in the First Bay correspond to the sampling sites of the investigation campaign (CS_2017).

\footnotetext{
* Corresponding author: francesca.sollecito@poliba.it
} 


\section{The investigation campaign}

One of the main concerns about the sediment characterisation has been that of allowing for the highest possible quality of soil sampling for the chemical, geochemical and geotechnical laboratory investigations. Cross-contamination, small changes in the storage temperature, light exposure and volatilization may influence the chemical analyses, which require strict protocols [5]. On the other hand, the sample remoulding and storage at temperatures below $+4^{\circ} \mathrm{C}$, could seriously compromise the quality of the geotechnical sampling [6]. In order to guarantee both high sampling quality and cost and time optimization for the in-situ campaign, the procedures for off-shore sampling, sample storage on the platform, transport and conservation of tube samplers and sub-sampling were properly defined [4], [7]. Fig. 2a shows the distribution scheme of samples among the chemical, geochemical, environmental technologist and geotechnical laboratories.

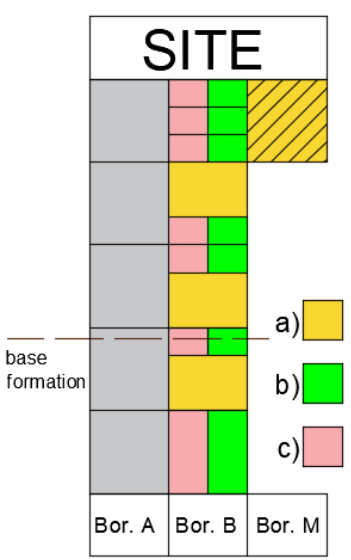

a)

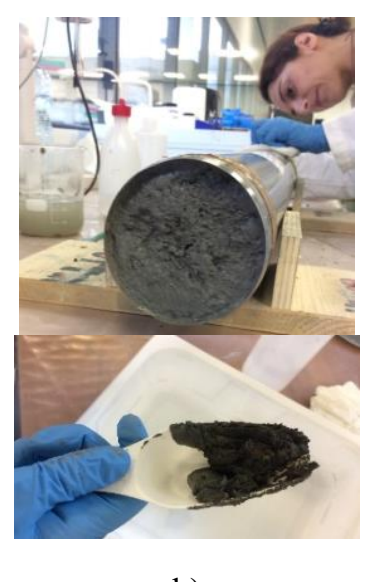

b)
Fig. 2. a) Schematic representation of the boreholes (A, B, M) retrieved for each site and of the sub-sampling along borehole B for geotechnical and chemical (a), chemical (b) and geological/geochemical (c) testing; b) Chemical sub-sampling of geotechnical samples.

For each of the 19 sampling sites in Fig. 1, two twin continuous boreholes, i.e. named A and B (Fig. 2a), were drilled at a maximum distance between each other of 10 $\mathrm{m}$. The sediments collected from borehole A were tested by researchers of environmental technology field, whereas those of borehole B were analysed by geologists and used for chemical, geotechnical and geochemical characterisation. The sample coring within the boreholes was carried out by means of $1.5 \mathrm{~m}$ length polycarbonate liners, specifically designed to avoid phenomena of crosscontamination of the sediment through common metallic corers. The polycarbonate liners taken from borehole B were longitudinally cut and the two cores were used for geological, geochemical and mineralogical analyses (first half), and for chemical testing (second half). Moreover, at fixed depths along borehole B, $1.4 \mathrm{~m}$ long undisturbed geotechnical samples were collected by means of different devices and methodologies as function of both the sampling depth and the soil consistency. The sediments of medium consistency were usually sampled using Osterberg hydraulic piston samplers, while either
Shelby or Denison tube piston samplers were used within stiffer sediment strata. The most polluted shallow layer of sediments $(0-1.5 \mathrm{~m}$ bsf $)$, characterized by very high liquidity index [8], was sampled down borehole M (Fig. 2a) by thin-walled tube samplers, made of transparent polycarbonate, pushed into the soil by a team of expert scuba divers. A portion of each undisturbed geotechnical sample was collected by chemists soon after sampling (Fig. 2b).

\section{Results}

\subsection{Geological and environmental features of the area}

The main geological units present in the basin from the bottom to the top are: Cretaceous limestone (Altamura limestone), Upper Pliocene-Lower Pleistocene calcarenites, (Gravina calcarenite, GRA), Lower Pleistocene clays (Sub-Apennine clays, ASP), Holocene alluvial deposits [9]. Except for limestone, during the CS_2017 for the first time several samples were collected from all the formations to reconstruct the geological setting of the basin and its litho-technical features. The two depressions of sub-elliptical shape that constitute the Mar Piccolo are supposed to be ancient river valleys that were incised in the basic formations during the continental phase related to the Last Glacial Maximum (20.00025.000 years BP, [10]). The valleys were subsequently submerged by the sea during the Holocene marine transgression. The sediments forming the Mar Piccolo basin have been deposited in time-varying environmental conditions, overlying both the ASP and the GRA. Moreover, the recent Carbon-14 dating results show that the top layer of sediments may have suffered a significant remoulding due to both the human activities carried out in the area (e.g. maritime activities and dragging of ship anchors in and around the harbour and the Navy) and the flooding events ([11], [12]).

In the last decade, several Authors (e.g. [13], [14]) have provided evidence that the Mar Piccolo submarine sediments contain high concentrations of pollutants. The chemical characterization carried out during the CS_2017, confirmed that heavy metals (e.g. $\mathrm{Hg}, \mathrm{Pb}$, As $\mathrm{Cd}, \mathrm{Cu}, \mathrm{Zn}$ ) and anthropic organic contaminants (e.g. PCBs, PAHs, HCs) in the sediments can even exceed the limits set by the law [15]. This is particularly the case within the shallow sediments $(0-3 \mathrm{~m}$ bsf $)$ in some areas of the First Bay [16]. Moreover, the chemical composition of the sediments is also affected by the presence of salt and organic matter. The seawater salinity of the Mar Piccolo ranges between $31 \mathrm{~g} / 1$ and $39 \mathrm{~g} / \mathrm{l}$ and the average salinity measured within the pore-fluid of the sediments is $30-32 \mathrm{~g} / 1$, even up to $18 \mathrm{~m}$ below the seafloor. Concentrations of total organic carbon up to $8 \%$ and higher than those of the Adriatic and Ionian open sea sediments (about $2 \%,[17]$ ), have been found in the top 3 m-layer of sediments by previous investigations [13]. During the last campaign (CS_2017), for the first time, also the organic matter (OM) was detected down to $43 \mathrm{~m}$ bsf in the sediment samples. OM (loss on ignition method, 
LOI, EPA 160.4) is found to be highly variable, although a general trend of reduction with depth is recorded: OM ranges between 9 and $18 \%$ within $1.5 \mathrm{~m}$ bsf, it is between 5 and $15 \%$, at medium depth (1.5-5m bsf) and tends to the average value of $7 \%$ at larger depth $(5-43 \mathrm{~m} \mathrm{bsf})$. The OM content and its correlation with soil composition can provide supporting information for interpretations of both natural and human-induced contamination [18]. Moreover, due to the small surface area and their negative charge, clay minerals have high attraction for organic or inorganic contaminants, therefore it is supposed that OM and contamination content can impact geotechnical features of sediments [19], [20].

\subsection{Composition and physical properties of the submarine sediments}

The classification of soil according its granulometric composition and its plasticity allows to recognise the engineering category to which it belongs. The geotechnical characterisation of the polluted sediments required the development of innovative solutions to consider the complexities deriving by the highly variable consistency of the sediments, the presence of shells, organic matter and pollutants, and the salinity of the pore fluid [21], [22].

The grading envelope of the 54 samples collected within the First bay of the Mar Piccolo basin (Fig. 3) essentially represents a fine-grained soil, for which the clay fraction, $\mathrm{CF}$, varies between 22.5 and $65.4 \%$, the sand fraction, SF, between 0.5 and $29.4 \%$ and the silt fraction, MF ranges from $30.5 \%$ to $69.5 \%$. Specifically, almost all the investigated specimens can be classified as clays with silts, or clayey silts, from sandy to slightly sandy, apart from three samples which testify the presence of a predominantly sandy matrix, located between 1.5 and $5 \mathrm{~m}$ bsf in the southwest area of the First Bay. It is worth noting that no significant differences in composition occur between the sediments of the shallow layer $(0-1.5 \mathrm{~m}$ bsf, red curves in Fig. 3) and those at lager depth (i.e. blue curves for $1.5-5 \mathrm{~m}$ bsf and black ones for $5-32 \mathrm{~m} \mathrm{bsf}$ sediments) [23]. The grading envelop also includes the Mar Piccolo samples belonging to the base formation represented by Sub-Apennine clays, ASP, (green dashed curve in Fig. 3). These data agree with those of the SubApennine clays collected in the Apulian region both inland (Pappadai Valley, [24]) and in the sea areas (Mar Grande basin, [25], [26]).

A widespread presence of illite, interstratified illite/smectite, I/S, and chlorite/smectite, $\mathrm{Chl} / \mathrm{S}$ has been detected within the clay fraction of three samples [8]. This finding is similar to what found for the ASP Formation outcropping in the Taranto area, where the clay minerals $(46 \%)$ are mainly represented by illite ([24] - [28]). All these evidences seem to suggest that there is no indication of significant differences in range of composition not only with depth throughout the basin but also between the recent sediments and the AGA Formation, from which the sediments were originated in consequence of geological processes (i.e. erosion and subsequent deposition, [9], [10]). However, the forthcoming data of mineralogical composition of the Mar Piccolo sediments will better clarify this aspect of the research.

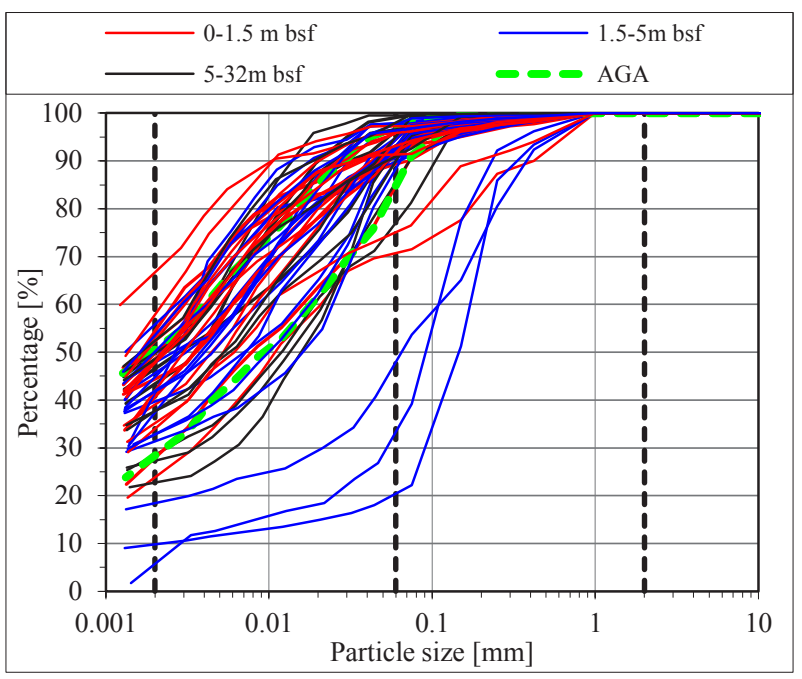

Fig. 3 Grading curves of the Mar Piccolo sediments.
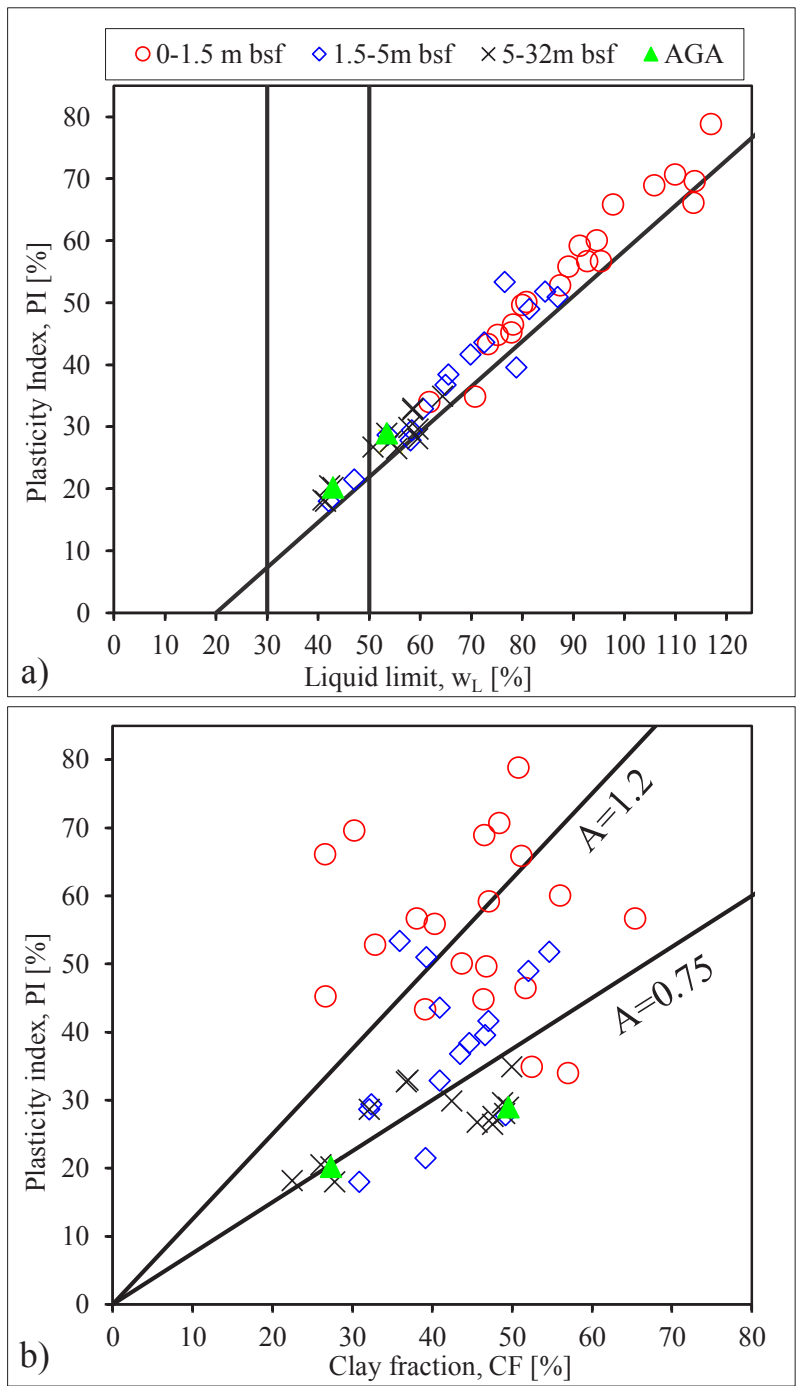

Fig. 4 Casagrande's plasticity chart (a) and Activity chart (b) of the Mar Piccolo sediments.

According to [29], the samples from the deeper (black $x$ in Fig. 4a), intermediate (blue rhombus in Fig. 4a) and AGA (green triangles in Fig. 4a) layers can be classified as fine soils from high $\left(50 \%<\mathrm{w}_{\mathrm{L}}<70 \%\right)$, to very high 
plasticity $\left(70 \%<\mathrm{w}_{\mathrm{L}}<90 \%\right)$, except for few samples having $\mathrm{CF}$ lower than $30 \%$ and $\mathrm{w}_{\mathrm{L}}$ lower than $50 \%$ (i.e. intermediate plasticity). In these layers (i.e. deep, intermediate, AGA), the activity for the samples ranges from low $(A=0.56-0.75)$ to medium values $(A=0.75$ 1.25), as reported in Fig. 4b. On the other hand, the shallow layer of the Mar Piccolo basin (red circles in Fig. $4 \mathrm{a}$ and $\mathrm{b}, 0-1.5 \mathrm{~m} \mathrm{bsf}$ ), where the pollutants reach values often above the legal limits and the organic matter content is high $(\mathrm{OM}=9-18 \%)$, is also characterised by huge variability and highest values of plasticity and activity indexes. In particular, within $1.5 \mathrm{~m}$ bsf, $\mathrm{w}_{\mathrm{L}}$ varies between 62 and $117 \%$, PI between 34 and $79 \%$ and A ranges from 0.60 to 2.49 (Fig. $4 \mathrm{a}$ and b). The activity of the shallow layer is also above the values expected for illitic mineralogy reported by [30] (i.e. Smectites $A=1-7$; Illite $A=0.5-1$; Kaolinite $A=0.5$ ). The variability of the index properties of the sediments is higher than that of the AGA Formation from which the sediments were originated, as measured either on in-land samples [24] or in submarine samples taken from both the Mar Grande ([25], [26]) and the Mar Piccolo basin (AGA samples). In particular, [25] report that the Mar Grande clays (sampling depth from 1 to $33 \mathrm{~m} \mathrm{bsf}$ ) are characterised by $\mathrm{w}_{\mathrm{L}}$ varying from 38 to $70 \%$, PI from 19 to $40 \%$, and activity values A from 0.49 to 0.93 . Similar values were found in the Sub-Apennine Clay Formation in the Pappadai Valley: $\mathrm{w}_{\mathrm{L}}=30-67 \%$; $\mathrm{PI}=11-37 \% ; \mathrm{A}=0.42-0.72$ [24].

In terms of in situ state, the sediment samples taken within the top $2-3 \mathrm{~m}$ bsf have generally natural fluid content much higher than the liquid limit: the liquidity index, LI, varies between 1 and $2.7\left(\mathrm{LI}_{\max }=4\right)$. In the layer of sediments between 3-5 m bsf, LI is still higher than one (i.e. liquid consistency), ranging between 1 and 2 , even when the real consistency of the retrieved material is clearly plastic. At larger depths (5-32m bsf), LI is either close to one or slightly smaller, indicating a plastic consistency. If compared to the ideal profile of reconstituted Pappadai Clays, the Mar Piccolo sediments exhibit high water content than expected for normally consolidated sediments under their own weight up to $20 \mathrm{~m}$ bsf ([5], [30]).

\subsection{Analysis of chemo-mechanical data correlations}

The effects on the geotechnical soil properties of physical-chemical factors, such as salinity and organic and inorganic compounds, are widely investigated in the literature (e.g. [26], [31] - [33]). According to [34], the potential of chemical-mechanical coupling resulted to be greatest in fine-grained soils at low confinement, as for the sediments here of reference, and such coupling may prompt highly variable effects for different clay fabric conditions. Nevertheless, in almost all the literature contributions, spiked monomineralic (e.g. kaolinite or smectite) soils are utilized. The investigation of the Mar Piccolo sediments may provide evidence about the effects of chemo-mechanical coupling phenomena for wellsorted (real) contaminated sediments.
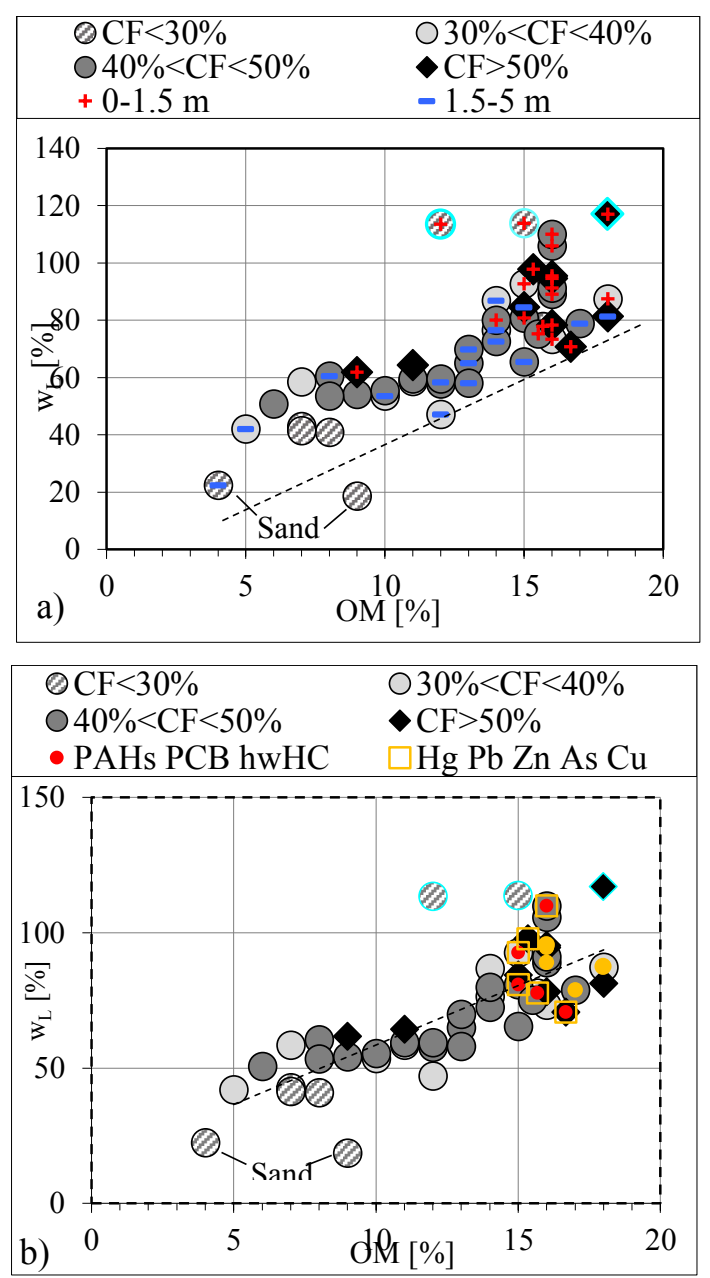

Fig. 5 Liquid limit, wL - organic content, OM, data of the Mar Piccolo sediments. Clay content values, sampling depth (a) and the most contaminated samples (b) are also indicated.

With this purpose, the geotechnical properties of the Mar Piccolo sediments were analysed in the light of the available data of organic matter, OM (determined by means of LOI method), heavy metals and organic pollutants concentration. The aim of the analysis was that of identifying correlations between the chemical and the geotechnical data able to explain some of the paradoxes recognised in the soil behavioural facets. As an example of the adopted approach, Fig. 5 shows the variability of liquid limit values, $\mathrm{w}_{\mathrm{L}}$ at different depths with respect to the organic matter, OM, measured according to LOI standards $\left(540^{\circ}\right.$ for 4 hours EPA 160.4$)$ on the Mar Piccolo sediments.

The colour intensity of the circular symbols in Fig. 5 has been chosen in order to take account of the range of clay fraction, CF. Moreover, black rhombuses in Fig. 5 indicate samples having the highest $\mathrm{CF}$, i.e. equal to or higher than $50 \%$. In the figure, the samples characterised by $\mathrm{CF}$ values lower than $30 \%$ (i.e. circles coloured with striped filling mode) include also two samples of sand $(\mathrm{SF}=67-80 \%)$. Furthermore, the samples taken from the top (0-1.5 $\mathrm{m} \mathrm{bsf}$ ) and the intermediate layer (1.5-5m bsf) have been distinguished by the inner symbols "+" and "", respectively (Fig. 5a). The other data refer to deeper samples (sampling depths from 5 to $32 \mathrm{~m} \mathrm{bsf}$ ). Three 
samples having the highest values of $\mathrm{w}_{\mathrm{L}}$ are marked with a light blue contour.

Fig. 5a shows that $\mathrm{OM}$ is higher in the top soils $(\mathrm{OM}=9-18 \%)$ and tends to reduce with depth, even if, along some boreholes, OM values are still high up to medium depth. Data from the literature testify that $\mathrm{OM}$ may absorb water and promote the aggregation of claysize particles to form a more open fabric [30]. If OM content increases, soils may be characterized by unusually high water contents and plasticity and activity indexes, with exceptionally low wet bulk densities (e.g. [35], [36], [37]). Consistently with the literature, the data show an increasing tendency of the liquid limit as the OM content increases (Fig. $5 b$ ):

$$
w_{L}=4.4 O M+14.6
$$

However, for $\mathrm{OM}>13 \%$ the dispersion of data tends to increase, irrespective of the content of clay, which usually strongly absorbs organic particles [18]. For same OM values, the samples from the top layer are characterised by higher liquid limit than the deeper ones, despite the latter may have similar (or even higher) CF. As an example, two black rhombuses in Fig. 5a, both characterized by $\mathrm{CF}>50 \%$ and the highest $\mathrm{OM}(18 \%)$, have quite different values of $\mathrm{w}_{\mathrm{L}}$, i.e. it is $117 \%$ in a top layer sample and $81 \%$ in a deeper one. This evidence seems to suggest that, beyond the OM and CF values, the soil response is influenced also by other factors.

The great variability of the liquid limit values is recorded in the shallow layer of contaminated sediments. However, the data of $\mathrm{w}_{\mathrm{L}}$ do not exhibit a clear tendency with respect to the increase of both organic pollutants (red points in Fig. 5b) and different groups of inorganic pollutants (yellow points for samples having high concentration of $\mathrm{Hg}, \mathrm{Pb}$; $\mathrm{Zn}$; yellow squares for samples with high concentration of $\mathrm{Hg}, \mathrm{Pb}, \mathrm{Zn}, \mathrm{As}, \mathrm{Cu}$ ). It is suggested that the combination of all these classes of contaminants, associated with the high level of OM and the pore-fluid salinity act in modifying the behaviour of samples in a complex way.

It is interesting to notice that the highest $\mathrm{w}_{\mathrm{L}}$ values are exhibited by three unpolluted samples (blue contour in Fig5a and b), that can also sustain high $\mathrm{w}_{\mathrm{L}}$ despite low CF. These samples are located near the northwest coast of the bay, where a steel factory (i.e. ILVA) pumping plant aspires sea water with a flux of $-20.8 \mathrm{~m}^{3} / \mathrm{sec}$ [16] with a relevant impact on the water circulation within the First Bay [11]. In addition, this area is rich in diatoms [38] and is dedicated to mussel cultivation that is characterised by a rich fouling community with considerable bioremediation capabilities [39]. Therefore, further studies will be carried out to verify if the hydrodynamic conditions within the basin may affect the soil sedimentation processes. Geochemical tests on both soil and pore fluid and scanning electron microscopy tests are currently on-going to understand if the presence of both peculiar sources of organic matter and microfossils or diatoms may contribute to explain the variability of the soil plasticity.

\section{Conclusion}

The characterization of the contaminated sediments in the Mar Piccolo basin (TA, South of Italy) highlighted the importance of the full integration between the geotechnical properties and the chemical and geochemical composition of the sediments, that has been possible only thanks to the coupled approach applied to the site characterisation, from the phase of sampling to that of sediment testing and data interpretation. Besides the relevance for the remediation project, the availability of a multidisciplinary database offered the possibility to find experimental evidences of the chemo-mechanical coupling in contaminated soils. Focusing on the soil plasticity, the data seem to suggest that the liquid limit tends to increase with the organic matter content. However, neither the concentration of the organic matter can explain alone the variability of the sediment plasticity nor a simple relation with the organic and inorganic contaminants is evident. Further investigations will aim to explore the effect of soil mineralogy and site conditions (i.e. deposition processes, pore fluid composition, state of organic matter and presence of mussel shells and microfossils) on the soil properties.

The activities were funded by the Special Commissioner for urgent measures of reclamation, environmental improvements and redevelopment of Taranto, Dr Vera Corbelli. The authors are grateful to the technician Angelo Miccoli for his help in experimental laboratory testing.

\section{References}

1. Italian Law n.426/1998, Nuovi interventi in campo ambientale (9 dicembre 1998)

2. C. Caroppo, L. Giordano, N. Palmieri, G. Bellio, A. Paride Bisci, G. Portacci, P. Scafani, T. Sawyer Hopkins, Progress towards sustainable mussel aquaculture in Mar Piccolo, Italy, Ecol Soc., 17, 3, 10 (2012)

3. Collaboration agreement between the Special Commissioner for urgent measures of reclamation, environmental improvements and redevelopment of Taranto and Politecnico di Bari (2014)

4. F. Cotecchia et al. An interdisciplinary study of a polluted marine system for an enhanced interpretation of the contamination conditions: the case of the Mar Piccolo (TA, south of Italy) (in prep.)

5. B. Schrefler, P. Delage, Environmental Geomechanics. ISTE Ltd and John Wiley \& Sons. (2010)

6. ASTM. Annual Book of ASTM standard, Part 19. Philadelphia (1976)

7. F. Cotecchia, F. Cafaro, M. Mali, D. Miccoli, D. Milella, G. Ruggieri, F. Sollecito, F. Todaro, C. Vitone, I - VI Geotechnical Reports: development strategies for remediation of the Taranto area, CS_2017 Report (2017) 
8. C. Vitone, A. Federico, A.M. Puzrin, M. Ploetze, E. Carrassi, F. Todaro F, Environ Sci Pollut Res 23, 12495 (2016)

9. S. Lisco, C. Corselli, F. De Giosa, G. Mastronuzzi, M. Moretti, A. Siniscalchi, F. Marchese, V. Bracchi, C. Tessarolo, A. Tursi, JOM, 1 (2015)

10. G. Mastronuzzi, Evoluzione dell'orografia antica della città di Taranto. Proc. "Dal Kastron bizantino al Castello aragonese", 123 (2006)

11. ARPA Puglia, Il Mar Piccolo di Taranto, Technical Report (2014)

12. G. Mastronuzzi, G. Agrosì, M. Moretti, E. Schingaro, N. Tempesta, Geological and Geochemical Data from Mar Piccolo, CS_2017 Report (2017)

13. ISPRA, Technical Report (2010)

14. N. Cardellicchio, A. Buccolieri, S. Giandomenico, L. Lopez, F. Pizzulli, L. Spada, Organic pollutants (PAHs. PCBs) in sediments from the Mar Piccolo in Taranto. Mar Pollut Bull, 55, 451 (2007)

15. Italian Law n. 152/2006, Norme in materia ambientale, (14 aprile 2006)

16. N. Cardellicchio, G. Mascolo, A. Tursi, Chemical, physical, microbiological and ecotoxicological analyses of sediments and biota from Mar Piccolo, CS_2017 Report (2017)

17. G. Bartholini, PhD Thesis (2015)

18. P.A. Meyers. \& J.L. Teranes, Sediment Organic Matter. Developments in Paleo-environmental Research, 2, 239-269 (2002)

19. M. Mali, M.M. Dell'Anna, L. Damiani, P. Mastrorilli, A.F. Piccinni. Assessment and source identification of pollution risk for touristic ports: Heavy metals and polycyclic aromatic hydrocarbons in sediments of 4 marinas of the Apulia region (Italy). Mar Pollut Bull, 114, 2, 768 (2017)

20. M. Mali, MM. Dell'Anna, M. Notarnicola, L. Damiani, P.Mastrorilli, Combining chemometric tools for assessing hazard sources and factors acting simultaneously in contaminated areas. Case study: "Mar Piccolo" Taranto (South Italy). Chemosphere. 184, 784-794 (2017)

21. F. Sollecito, F. Cotecchia, M. Mali, D. Miccoli, C. Vitone, Geotechnical investigation of submarine sediments for the environmental characterisation of a contaminated site, Proc. CPEG2, Leeds, UK (2017)

22. F. Sollecito, F. Adamo, G. Andria, O. Bottiglieri, F. Cotecchia, A. Di Nisio, A.M.L. Lanzolla, D. Miccoli, M. Spadavecchia, F. Todaro, C. Vitone, An Innovative System for Testing of Contaminated Soft Sediments 2018 IEEE METROSEA, Bari, Italy (2018)

23. F. Sollecito, F. Cotecchia, C. Vitone, Peculiar geotechnical properties of submarine sediments from a polluted site, Proc. IARG, Genova (2018)
24. F. Cotecchia, PhD thesis, Imperial college of Science, Technology and Medicine, London University, London (1996)

25. V. Cotecchia, Caratterizzazione geologica $e$ geotecnica dei terreni pertinenti alla vasca di contenimento e alle opere a detto fine previste, Geol.Geotech. Report, APT (2005)

26. A. Federico, C. Vitone, A. Murianni, Can. Geotech. J, 52, 12, 2030 (2015)

27. A. De Marco, M. Moresi, G. Nuovo, Le argille dei bacini di Taranto e di Grottaglie-Montemesola: caratteri granulometrici, mineralogici e chimici, SIMP, 37, 241 (1981)

28. A. Federico, A. Murianni, E. Miccoli, C. Vitone, M. Nobile, G. Internò, Preliminary experimental results on the stabilization of dredged clayey sediments from the Port of Taranto. TC 215 CPEG 2013. Proc. of the Sym. on Coupled Phen. in Env. Geo., Turin, Italy. Edited by Manassero et al., 655 (2013)

29. BS 1377. Methods of test soils for civil engineering purposes. Classification tests

30. J.K. Mitchell, K. Soga, Fundamental of soil behaviour. Wiley, New York. 3rd ed (2005)

31. C. Di Maio, L. Santoli, P. Schiavone, Mechanics of materials, 36, 435 (2004).

32. M. Calvello, M. Lasco, R. Vassallo, C. Di Maio, Compressibility and residual shear strength of smectitic clays: influence of pore aqueous solutions and organic solvents, RIG 1, 34 (2005)

33. J. Chen, A. Anandarajah, H. Inyang, J Geotech Geoenviron, 126, 9, 798 (2000)

34. J.C. Santamarina, K. Klein, A. Palomino, M.S. Guimaraes, Micro-Scale aspects of chemicalmechanical coupling: interparticle forces and fabric. Proc. of the Workshop on Chemo-mechanical coupling in clays: from nanoscale to engineering applications. 47 (2002)

35. G.H. Keller, Geo-Mar. Lett, 2, 191 (1982)

36. R.H. Bennett, L. Lehman, M.H. Hulbert, G.R Harvey., S.A. Bush, E.B. Forde, P. Crews, W.B. Sawyer, Mar Georesour Geotec, 6, 1, 61 (1985)

37. C.L. Levesque, J. Locat, S. Leroueil, Characterisation of postglacial sediments of the Saguenay Fjord, Quebec, Canada. Taylor \& Francis Group, London, 3, 2645 (2007)

38. F. Rubino, T. Cibic, M. Belmonte, M. Rogelja, Environ Sci Pollut Res, 23, 13, 12624 (2016)

39. L. Draughon, J. Scarpa, P. Keating, L. Hartmann, Potential estuarine water quality improvement via marine invertebrate bioremediation. In Environmental Awareness and Management; Theophanides M. and Theophanides T., Eds.; ATINER: Athens, 97 (2008) 